\title{
Elementos de Sustentabilidade na Cadeia de Suprimento: Um Estudo no Setor de Energia Solar
}

\author{
Elements of Sustainability in the Supply Chain: A Study in the Solar Energy Sector
}

\author{
Mariana Fernandes Alves ${ }^{1}$ \\ Minelle Enéas da Silva ${ }^{2}$
}

\begin{abstract}
Resumo
Buscando contribuir com o avanço das pesquisas de sustentabilidade na cadeia de suprimento no Brasil, é necessário realizar estudos com forte contribuição para o desenvolvimento local. Assim sendo, com ênfase em energias renováveis, o objetivo deste estudo é identificar como a sustentabilidade vem sendo introduzida na cadeia de suprimento de energia solar no Ceará, utilizandose os elementos de pesquisa de Beske e Seuring (2014). Para tanto, uma pesquisa qualitativa foi desenvolvida com três diferentes díades, consideradas aqui unidade de análise. As entrevistas foram realizadas com fornecedores, clientes e atores não tradicionais, além de uma análise estruturada em cinco categorias: orientação, continuidade, colaboração, gestão de risco e pró-atividade. De modo geral, notou-se que a maioria das empresas focais demonstra entender o significado de sustentabilidade, no entanto há um relacionamento fraco entre os membros da cadeia de suprimento, o que demonstra que as estratégias de sustentabilidade não são bem delimitadas. A pesquisa avança na contextualização da sustentabilidade para o estudo da cadeia de suprimento no Brasil, demonstrando que (1) existem limites na aplicação de modelos internacionais que lidam com o tema, e (2) o setor de energia solar deve impulsionar a introdução da sustentabilidade por meio de ações mais efetivas.
\end{abstract}

Palavras-chave: Sustentabilidade. Cadeias de suprimento. Díades. Energia solar.

\begin{abstract}
Seeking to contribute to the advancement of sustainability research in the supply chain in Brazil, it is necessary to carry out studies with a solid contribution to local development. Therefore, with an emphasis on renewable energies, the objective of this study is to identify how sustainability has been introduced in the solar energy supply chain in Ceará, using the research elements of Beske and Seuring (2014). Therefore, qualitative research was developed with three different dyads, considered here as a unit of analysis. Interviews were conducted with suppliers, customers, and non-traditional actors, in addition to an analysis structured into five categories: guidance, continuity, collaboration, risk management, and pro-activity. In general, it was noted that most focus companies demonstrate an understanding of the meaning of sustainability; however, there is a weak relationship between members of the supply chain, which shows that sustainability strategies are not well defined. The research advances in the contextualization of sustainability for the study of the supply chain in Brazil, showing that (1) there are limits in the application of international models that deal with the subject, and (2) the solar energy sector should drive the introduction of sustainability through more effective actions.
\end{abstract}

Keywords: Sustainability. Supply chains. Dyads. Solar energy.

\footnotetext{
19 Mestra em Administração pela Universidade de Fortaleza. Consultora Financeira para Micro e Pequenas Empresas no Ceará. Federal do Rio Grande do Sul.
} 


\section{INTRODUÇÃO}

A busca pela sustentabilidade deixou de ser um diferencial para se tornar essencial nas empresas, considerando que os investidores mundiais preferem empresas sustentáveis, devido à sua maior preparação para possíveis riscos (Caparelli, 2010; Greene, 2003). A discussão sobre sustentabilidade traz em seu conceito o termo Triple Bottom Line (TBL) para facilitar a compreensão de que são três os aspectos que constroem sua base: ambiental, social e econômico (Elkington, 2002). A construção de uma imagem positiva da empresa está ligada intimamente a esses três elementos, devendo todos ser observados durante todo o processo produtivo, desde medir resultados, até o âmbito de sua responsabilidade objetiva perante os consumidores (Careta \& Maria, 2018).

A importância da sustentabilidade vai além de ações responsáveis das empresas, pois seu conceito complementase ao do desenvolvimento sustentável, fazendo, dessa forma, com que as ações ambientais, sociais e econômicas observem a preservação das gerações presentes e futuras, garantindo responsabilidade na exploração de recursos naturais (Munk, Dias \& Sousa, 2010; Laureano, 2012). Percebe-se, portanto, a relevância da sustentabilidade, que agrega, além de um melhor desempenho na empresa, a preocupação com o meio ambiente e o desenvolvimento responsável na sociedade. Nesse cenário, é compreensível que estudos no tema sejam estendidos para além do funcionamento interno das empresas, ingressando na discussão das cadeias de suprimento (Abdala \& Barbieri, 2014; Alves, Silva \& Santos, 2018; Silva \& Nascimento, 2016).

Uma cadeia de suprimento se refere ao conjunto de atividades responsáveis pela criação do produto, desde o suprimento das matérias-primas à entrega ao consumidor final (Lummus \& Vokurka, 1999; Ballou, Gilbert \& Mukherjee, 2000). Cada elo desse relacionamento tem grande relevância no sucesso do produto, sendo fundamental que exista integração entre eles (Brito \& Berardi, 2010). Com as discussões sobre sustentabilidade, destacou-se a importância de uma reorganização deste modelo, a fim de avaliar questões socioambientais, pois, além de fomentar o desenvolvimento sustentável e gerar maior eficiência, fez-se necessário, ainda, a proteção da imagem da organização (Seuring \& Müller, 2008). Surge desse modo o conceito de Sustentabilidade em Cadeias de Suprimento (SCS).

A SCS vem sendo apresentada na literatura em diversos cenários (Ahi \& Searcy, 2013; Pagell \& Wu, 2009; Silva, Fritz \& Nunes, 2017). Uma das formas que tem se intensificado é a busca por sua operacionalização. Neste sentido, Beske e Seuring (2014) trazem um conjunto de categorias e elementos que podem ser implementados na gestão da cadeia de suprimento em relação à sustentabilidade. Existem outros modelos de pesquisa com o mesmo intuito (Ansari \& Kant, 2017), no entanto entende-se que este em especial apresenta elementos centrais para entender SCS. Além disso, Khalid et al. (2015) indicam que este modelo pode auxiliar na compreensão de estudos em contexto de base da pirâmide e, apesar de não ser o foco desta pesquisa, a busca por evidências empíricas para o estudo de SCS é necessária.

Considerando que o Brasil apresenta grande potencial em relação ao mundo na busca por fontes de energias renováveis, esta pesquisa enfoca os elementos de SCS no contexto da energia solar. Justifica-se a escolha do setor por este estar em constante crescimento. O Brasil é um país de privilegiada localização para a exploração solar, ou seja, estima-se que em 25 anos a energia eólica e solar do país supere a matriz energética das hidreléricas (Mendes et al., 2017). Aliado a isto, é, ainda, uma forma de energia limpa, ou seja, grande aliada na proteção ambiental, utilizando-se de recursos renováveis e ajudando na preservação de recursos naturais. A pesquisa centra seu estudo no estado do Ceará, que é um dos que mais recebe a incidência de raios solares por sua localização geográfica.

A partir dessas considerações, o presente estudo tem como objetivo identificar como a sustentabilidade vem sendo introduzida na cadeia de suprimento de energia solar no Ceará, utilizando-se os elementos de pesquisa de Beske e Seuring (2014). Para tanto, o foco da pesquisa está em três díades na cadeia de suprimento. Será demonstrado, portanto, dentro do setor de energia solar, a relação entre a empresa focal e o cliente, ou seja, quem fornece a placa solar e quem compra a placa solar. De forma complementar, foram estudados atores não tradicionais, no sentido de identificar elementos que estão no entorno das relações estudadas e contribuem para entender o contexto de pesquisa. $\mathrm{O}$ estudo demonstra que nem todas as cinco categorias presentes no modelo estudado facilitaram entender o tema na prática, todavia diversos dos elementos foram verificados na prática das empresas estudadas.

Demonstra-se, dessa forma, a importância do estudo na relação entre sustentabilidade e gestão da cadeia de suprimento. Assim, ao utilizar o modelo de Beske e Seuring (2014), que tem crescente aplicação em pesquisas de SCS, este estudo demonstra originalidade em dois pontos principais: (1) amplia-se o debate sobre SCS para diferentes setores, como é o caso do setor de energia solar, algo pouco realizado na literatura nacional e internacional; e (2) realiza-se uma análise crítica do modelo para o contexto local, o que ainda é pouco explorado na literatura. As pesquisas até então realizadas, ou se centram em uma única dimensão, ou apresentam a análise do modelo de uma forma superficial. Para uma melhor compreensão do estudo, após a discussão teórica apresentada a seguir, têm-se os procedimentos de pesquisa e os resultados que demonstram o entendimento do modelo em sua especificidade. Por fim, são apresentadas discussões, conclusões e contribuições identificadas. 


\section{REFERENCIAL TEÓRICO}

O crescente foco no tema da sustentabilidade aumenta a importância do estudo, tendo em vista que seguir um caminho sustentável passa a ser algo imprescindível. Isto se demonstra na preocupação global em volta do tema, pois este vem sendo foco de diversos encontros promovidos por entidades internacionais de direito público, como Comissão Mundial sobre Meio Ambiente e Desenvolvimento (Comissão de Brundtland), Rio-92, Rio+10 e Rio+20. Todos esses encontros estão centrados na discussão da degradação ambiental e o dever de proteger a integridade ecológica para, então, chegar ao equilíbrio e bem estar social (Feil \& Schreiber, 2017). Uma empresa que não está de acordo com o exigido para uma utilização consciente e que preserve a natureza, em equilíbrio com o crescimento econômico, deixa de ser respeitada no campo de investimentos, deixando de ter credibilidade.

\subsection{Sustentabilidade na Cadeia de Suprimento (SCS)}

A SCS deve ser analisada tanto pelo seu desenvolvimento econômico, quanto pelo seu desempenho socioambiental (Beske, 2012; Pagell \& Wu, 2009; Seuring \& Müller, 2008). A sustentabilidade deve ser interpretada utilizando-se diversas perspectivas. Na econômica incide, principalmente, na geração de trabalho, distribuição de renda e desenvolvimento de tecnologias que aperfeiçoem a produtividade sem destruir os recursos naturais (Magon et al., 2018). No que diz respeito à dimensão social, esta destaca o protagonismo humano, tendo como maior preocupação seu bem-estar. Já na esfera ambiental, o foco está em diminuir o impacto ao meio ambiente causado pela ação humana (Bubicz et al., 2019; Stoffel \& Colognese, 2015). Todavia, outros elementos podem ser considerados. Para Fritz e Silva (2018), aspectos culturais e institucionais podem complementar o tema, uma vez que a SCS na América Latina deve considerar entre outros aspectos o desenvolvimento local.

De forma geral, os aspectos ambientais e sociais ao longo da Cadeia de Suprimento (CS) devem ser levados em consideração, evitando problemas relacionados, mas também olhando produtos e processos mais sustentáveis (Seuring \& Müller, 2008). Para se tornar sustentável, então, a cadeia de suprimento deve incluir a sustentabilidade nos processos de gestão, considerando os impactos ambientais, sociais e econômicos das atividades empresariais (Brito \& Berardi, 2010; Carvalho, 2011). São diversos os conceitos que norteiam o entendimento do tema. Para esta pesquisa, entende-se SCS como "ações gerenciais específicas realizadas para tornar a cadeia de suprimento mais sustentável, com o objetivo final de criar uma cadeia verdadeiramente sustentável” (Pagell \& Wu, 2009, p.38). Desse modo, entende-se que a sustentabilidade não é um destino em si, mas uma prática contínua que precisa ser parte das ações diárias de organizações em uma CS (Silva e Figueiredo, 2020).

Existem diversas formas para se identificar a implementação de SCS, dentre as quais se destacam: identificar a existência de coordenação entre os membros da cadeia (Alves, Schultz e De Barcellos, 2018); mensuração de ações de redução de impacto (Adesanya et al., 2020; Schrette et al., 2014); identificar estratégias usadas por organizações no gerenciamento de seus fornecedores (Harms, Hansen e Schaltegger, 2013); análise de recursos e capacidades (Neutzling e Silva, 2016); estudo sobre mecanismos de governança (Jia et al., 2018); análise de seleção de fornecedores (Rashidi et al., 2020); etc. Apesar desta multiplicidade de abordagens, o número de estudos conduzidos em países tidos como em desenvolvimento ainda precisa de maior ênfase na literatura (Fritz e Silva, 2018; Jia et al., 2018). Com esta perspectiva, Pagell and Shevchenko (2014) sugerem que pesquisas precisam ampliar sua visão crítica para reforçar o nível de impacto e representatividade em múltiplos contextos.

\subsection{Elementos de sustentabilidade na cadeia de suprimento}

Para avançar no assunto, o presente artigo traz uma discussão sobre SCS a partir do framework desenvolvido por Beske e Seuring (2014). Tal modelo parte da ideia de que a sustentabilidade na cadeia de suprimento visa aperfeiçoar a exploração de recursos, a fim de minimizar o desperdício e aumentar a rentabilidade (Beske \& Seuring, 2014). Para os autores, os elementos de SCS poderão ter maior desempenho, se forem implementadas a partir de níveis hierárquicos (estratégico, estrutura e processos). Ansari e Kant (2017) avaliam vários modelos desenvolvidos na literatura e destacam ser necessário ampliar o estudo de modelos específicos para que a literatura da área ganhe maturidade. Roy, Schoenherr e Charan (2018) ratificam tal visão indicando que a discussão sobre elementos de SCS estão atualmente limitados à sua adoção, com pouca análise sobre sua implementação, o que é ênfase desta pesquisa. Acredita-se que ampliar o entendimento de como a sustentabilidade é implementada favorece uma visão mais clara e pertinente no estudo de cadeia de suprimento.

O modelo selecionado demonstra que as empresas que seguem sustentabilidade em sua estratégia de negócios usam as citadas categorias, que estão intimamente relacionadas à questão da qualidade das relações dentro da cadeia (Beske \& Seuring, 2014; Sauer and Seuring, 2017). Beske e Seuring (2014) trazem em sua pesquisa cinco categorias para implementar SCS. São elas: orientação, continuidade, colaboração, gestão de riscos e pró-atividade (Figura 1). No entanto, em uma pesquisa posterior, Khalid et al. (2015) identificam que algumas dessas categorias talvez não façam parte do modelo final, o que pode suportar os argumentos desta pesquisa. Além disso, esses mesmos 
autores indicam que pró-atividade deve estar relacionada à gestão, o que muda o nome das categorias para gestão de pró-atividade. Tal visão foi ratificada por Silva et al. (2020) em sua pesquisa sobre o modelo.

Figura 1 - Categorias e elementos de Sustentabilidade em Cadeias de Suprimento

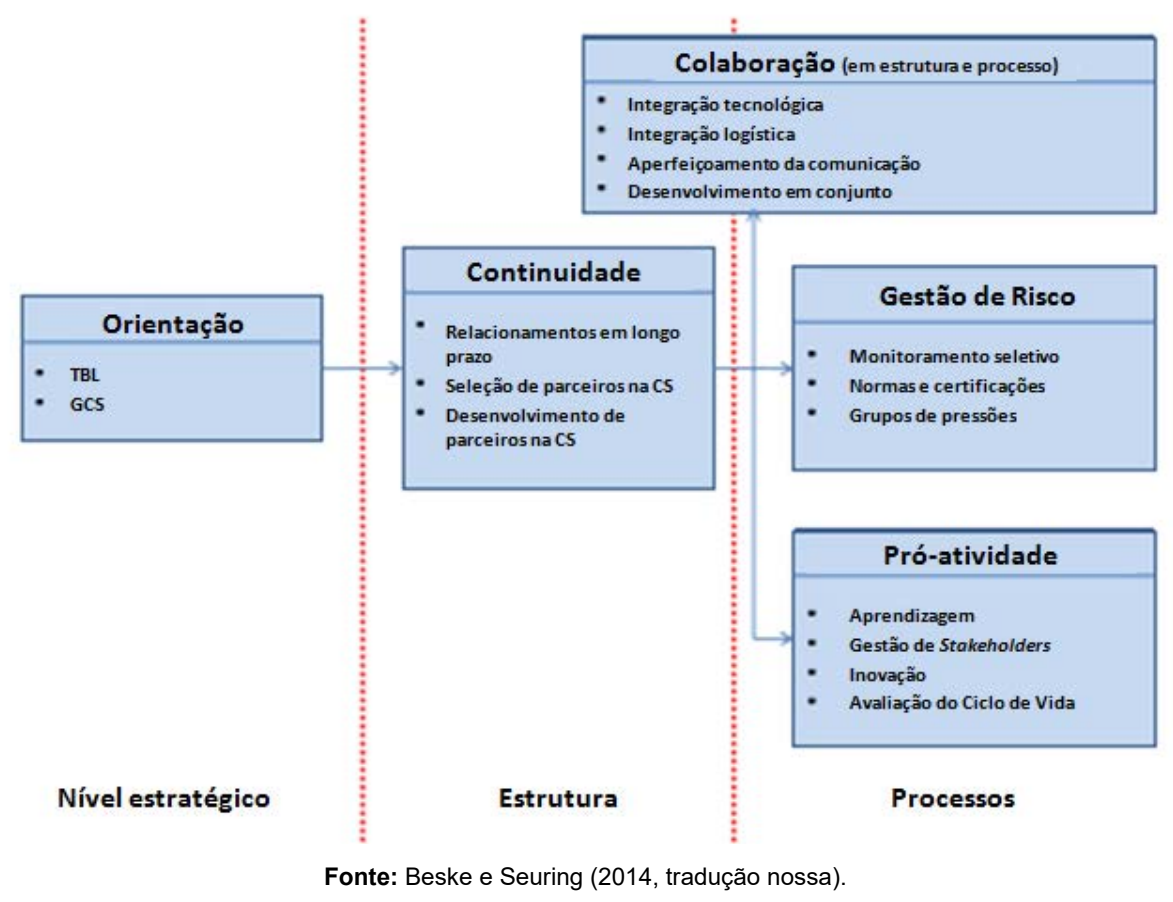

Para Beske e Seuring (2014), a categoria Orientação consiste em uma dedicação ao Supply Chain Management (SCM) e ao TBL por uma organização. Implica em integrar a sustentabilidade na formulação de estratégia, a fim de alcançar uma vantagem. Já a categoria Continuidade refere-se às relações que são usadas para construir a confiança e o compromisso (Pagell \& Wu, 2009), ou seja, a criação e manutenção de relações em longo prazo. Quanto à Colaboração, trata-se da prática que observa a forma que ocorre o encadeamento da integração dos parceiros, e considera a qualidade de informações compartilhadas e como são feitas. No que se refere à categoria Gestão de Risco, compreende-se como as práticas de gerenciamento de riscos. Por último a categoria Pró-atividade é vista como novos processos ligados à aprendizagem.

Vale salientar que pesquisas vêm aplicando o modelo em todo ou parte, o que auxilia na construção desta pesquisa. Sauer e Seuring (2017) buscam debater sobre o modelo no setor mineral e entendem ser necessário ampliar o debate para acrescentar outros atores, como é o caso do governo. Alves et al. (2018) pesquisaram uma cadeia de manufatura interessados na colaboração entre empresas. De forma similar, Azevedo et al. (2018) estudaram colaboração sob a perspectiva de cadeias focadas em relações cooperadas e para ambas as pesquisas a colaboração é central à sustentabilidade. Silva et al. (2020) pesquisaram o nível estratégico do modelo demonstrando que empresas focais podem introduzir sustentabilidade em dois sentidos: puxado pelo mercado (market-driven) ou incentivando o mercado (market-driver). De forma similar, Ponte e Viana (2020) estudam as influências do mercado na orientação estratégica de empresas voltadas à SCS. Adicionalmente, Vasconcelos, Viana e Souza (2021) conectaram o modelo em questão à economia circular, apresentando nova contribuição ao debate. Dessa forma, a partir do estudo proposto no presente artigo, evidências empíricas contribuirão com a literatura de SCS, ao se buscar identificar nuances do modelo a um contexto específico.

\section{PROCEDIMENTOS METODOLÓGICOS}

Com o objetivo de identificar como a sustentabilidade vem sendo introduzida na cadeia de suprimento de energia solar no Ceará, a pesquisa classifica-se como qualitativa em relação a sua abordagem (Creswell, 2007; Godoy, 2006). A pesquisa qualitativa identifica como atividade o pesquisador que se coloca no mundo na busca de acontecimentos da prática social para o avanço do estudo (Denzin \& Lincoln, 2000). Esse tipo de pesquisa possibilita compreender o fenômeno social em sua complexidade, implantando-se no cenário no qual o fenômeno ocorre. Quanto aos objetivos, a pesquisa caracteriza-se como descritiva, tendo como finalidade descrever características de determinado fenômeno, a partir de uma temática pouco discutida (Gil, 2010).

Com base nisso, utilizou-se a estratégia de estudo de caso por meio de uma abordagem investigativa empírica que analisa as relações de um determinado fenômeno; sem abrir mão do contexto ambiental na qual está ocorrendo 
(Seuring, 2011; Pagell \& Schevchenko, 2014; Yin, 2015); devendo, assim, o tema ser analisado com profundo interesse, na busca de um entendimento completo sobre sua natureza e circunstâncias, com coleta de dados e aprofundamento de seu conteúdo (Yin, 2015; Sampieri, Collado \& Lucio, 2006). Dessa forma, busca-se, na leitura dos dados, o aprofundamento necessário para elucidar a compreensão das ações de sustentabilidade, pois, para esta pesquisa, toma-se a cadeia de suprimento de energia solar como o nível de análise, composto por um conjunto de unidades de análise - as díades.

O presente estudo é formado por diferentes unidades de análise; enquanto os sujeitos da pesquisa são formados por três empresas fornecedoras de placas solares (E1, E2 e E3), quatro empresas compradoras de placas solares (C1, C2, C3 e C4), e três membros de incentivo à aquisição de placas solares, denominados na pesquisa de atores não tradicionais (ANT1, ANT 2 e ANT 3). Foram realizadas entrevistas individuais com os atores envolvidos, com duração média de 43 minutos, estando todos os sujeitos localizados no estado do Ceará. O processo de identificação se deu por intermédio de pesquisas sobre empresas fornecedoras de placas solares e seus respectivos clientes, juntamente com a identificação das organizações que fomentam o setor de energia solar no Ceará de outubro de 2017 a maio de 2018.

Para a pesquisa, ainda, foram realizadas visitas ao campo e coleta de documentos publicados sobre o setor de energia solar. Dessa forma, ratifica-se que a díade foi selecionada a fim de analisar a relação entre a empresa focal e seus clientes diretos, visto que a associação diádica é o relacionamento entre duas partes (Pereira \& Bellini, 2006), tendo o foco da pesquisa na cadeia direta, como proposto por Mentzer et al. (2001).

Os respondentes da pesquisa foram os responsáveis pelos setores estratégicos das organizações, ou seja, responsáveis pelas decisões, e optaram por não revelar os nomes das empresas, a fim de preservar sua identidade.

Finalizada a coleta, partiu-se para a análise dos dados. Nesse momento da pesquisa utilizou-se a análise de conteúdo dedutiva (Mayring, 2003), com o propósito de encontrar elementos associados às cinco categorias do modelo proposto por Beske e Seuring (2014). As entrevistas foram transcritas, organizadas e estruturadas. Assim, como forma de reforçar a abordagem de teste de teoria (Ketokivi e Choi, 2014), buscou-se uma exploração a partir de categorias de análise previamente definidas e identificadas no referencial teórico, quais sejam: orientação, continuidade, colaboração, gestão de risco e pró-atividade. Além disso, como critério de qualidade da pesquisa para as entrevistas, foi utilizado um protocolo de estudo de caso no sentido de proporcionar confiabilidade aos dados adquiridos (Yin, 2015). Por fim, a legitimidade da pesquisa se deu a partir de validade de construto e externa, com a realização de análises por mais de um pesquisador, cujos resultados serão apresentados a seguir.

\section{ANÁLISE DOS RESULTADOS}

\subsection{Contexto de pesquisa}

A energia solar é a fonte de energia que mais cresce no mundo. Historicamente, foi em 1838, quando se observou o efeito fotovoltaico. No ano de 1865 , criou-se a primeira máquina capaz de converter a energia solar em energia mecânica. Mais tarde, veio a criação do primeiro dispositivo de fotoprodução de eletricidade. O século XX foi importante na evolução da energia solar, especialmente nos anos 1970, no qual Exxon Corporation, uma empresa de petróleo e gás, passou a produzir mais painéis solares cada vez mais eficientes e com menor custo, capazes de atender à sociedade, recebendo incentivo do Governo Norte-Americano à utilização de energia solar. Já no ano de 1996, foi iniciado o desenvolvimento de plantas de energia solar em alta escala, o que proporcionou a produção crescente que se percebe na atualidade.

Em relatos históricos acerca da evolução da energia solar no Brasil, tem-se como primeiro evento relevante a criação da Lei de Eficiência Energética, que trata de investimentos em pesquisa e desenvolvimento, além de eficiência energética por parte das empresas concessionárias, permissionárias e autorizadas do setor de energia elétrica. No ano de 2004, mudanças importantes foram implantadas para a evolução da energia solar; como a redução das tarifas de uso dos sistemas elétricos de transmissão e de distribuição, o Lançamento do Fundo Constitucional de Financiamento do Nordeste (FNE), e a instituição do Programa de Incentivo às Fontes Alternativas de Energia Elétrica (Prolnfra); que promoveu a implantação de 144 usinas no Estado do Ceará, sendo sancionada a Lei Complementar n.81/09, que cria o Fundo de Incentivo à Energia Solar no Estado do Ceará (FIES), apenas cinco anos depois.

Logo após a inauguração da primeira usina do Brasil, o Ministério de Minas e Energias publicou o trabalho Estudo e Propostas de Utilização de Geração Fotovoltaica Conectada à Rede, em particular em edificações urbanas, que apresenta recomendações sobre o uso de painéis fotovoltaicos e propõe incentivos à utilização destes painéis. No ano seguinte, a Agência Nacional de Energia Elétrica (Aneel) editou a Resolução 482, que dá as condições gerais para o acesso de microgeração e minigeração distribuída aos sistemas de distribuição de energia elétrica, o que possibilitou que qualquer consumidor o poder de conectar um sistema gerador de energia elétrica próprio, oriundo de fontes renováveis, cuja energia captada por ele poderá ser emprestada à concessionária e compensada sobre seu consumo de energia. 
Outro importante marco para o crescimento da energia solar no Brasil ocorreu em 2015, quando o Conselho Nacional de Política Fazendária (Confaz) cancelou portaria que obrigava a tributação de energia solar, fazendo com que cada Estado pudesse decidir se cobrariam ou não o Imposto de Circulação de Mercadoria de Serviços (ICMS) pela energia solar, o que possibilitou a criação da Lei Estadual 31.953/15, no Ceará, que alterou o Decreto 24.569/97 e regulamentou a Lei 12.670/97, concedendo a isenção do ICMS nas operações relativas à circulação de energia elétrica que utiliza fontes com base solar. Neste mesmo ano, a Aneel publicou a Resolução 687, que atualiza a Resolução 482, que tornou mais atrativo ao público a ideia de produção da própria energia por aumentar as vantagens e possibilidades da compensação de crédito.

Sabe-se que o Brasil recebe uma irradiação superior a 3000 horas/ano, sendo a região Nordeste a mais privilegiada, com incidência média diária entre 4,5 a $6 \mathrm{kWh}$, fazendo o país possuir a maior taxa de irradiação solar do mundo. Apesar disso, a primeira usina de energia solar do país, instalada no município de Tauá, no Ceará, foi inaugurada apenas em 2011. A energia solar, então, passou a crescer e tornar-se uma realidade não apenas para grandes empresas, mas também para consumidores comuns de energia, colocando como ponto crucial para tantos incentivos governamentais. Assim, o aumento dessa cultura de utilização de recursos renováveis é um importante passo para o avanço energético do país, que é rico em inúmeros recursos naturais e ainda precisa crescer em relação à sua consciência energética.

\subsection{Elementos de sustentabilidade na cadeia de suprimento de energia solar}

Para o desenvolvimento desta pesquisa, tomou-se como foco díades que compõem o setor no estado do Ceará. O estudo focou entender os elementos do modelo de Beske e Seuring (2014) e sua contribuição para entender o tema. O Quadro 1, a seguir, apresenta os resultados da pesquisa de forma geral. Como se pode observar, são relacionadas as falas de todos os atores envolvidos na pesquisa no intuito de entender as relações proposta para cada aspecto. E, em seguida, é possível identificar uma análise de acordo com cada categoria.

Quadro 1 - Resultados da Pesquisa

\begin{tabular}{|c|c|}
\hline Categorias & Principais Depoimentos \\
\hline Orientação & $\begin{array}{l}\text { "Essa questão de estratégia a gente não é muito de fazer propaganda, a gente é muito 'boca a boca' mesmo tipo o cliente } \\
\text { ficou satisfeito e indicou para outras pessoas, então assim a nossa empresa funciona mais dessa forma." (E1) } \\
\text { "Sim isso aí não é só comigo essa parte estratégia, marketing, a gente tem, inclusive a nossa missão, vamos dizer assim. } \\
\text { É.. a locomotiva que a gente chama é própria sustentabilidade em si, então a gente procura se basear sempre nisso, só } \\
\text { que na questão das contratações tudo a gente tenta colocar em primeiro lugar a sustentabilidade." (E2) } \\
\text { "Existe! Existe... A gente sempre passa para o cliente numa conjuntura comercial, os benefícios que ele vai ter. É o que a } \\
\text { gente sempre fala. A energia solar na questão social, econômica e ambiental [....]." (E3) } \\
\text { "[...] a gente tem se envolvido muito com quem discute direitos humanos. Hoje aqui no Ceará e no Brasil, né, quem discute } \\
\text { justiça, justiça ambiental, sobretudo, e direitos humanos e pra gente a melhor estratégia que a gente tem tentado construir } \\
\text { junto... é... é estar junto das populações tradicionais costeiras, que é o nosso público hoje, né." (ANT2) }\end{array}$ \\
\hline Continuidade & $\begin{array}{l}\text { "E a garantia também é dadas por eles, então qualquer problema, que ainda não deu, mas se tiver a gente vai ter que } \\
\text { manter essa relação sim." (E2) } \\
\text { "Relação de fornecedor, cliente! Me dê o seu produto e me dê o seu dinheiro. Tá entendendo? Não tem muito é ... relação } \\
\text { assim boa comercialmente, tem que manter, mas é uma relação de qualquer empresa. Qualquer cliente e fornecedor, } \\
\text { cumprir expectativas que eu vou continuar comprando de você tá entendendo?" (E3) }\end{array}$ \\
\hline Colaboração & $\begin{array}{l}\text { "Novas tecnologias, novos equipamentos, demandas de financiamento de banco... impostos quando há algum incentivo." (E2) } \\
\text { "É... a parte de pós-venda, né? A parte de pós-venda dos equipamentos, a ciência. Eu sempre recebo do fabricante } \\
\text { equipamentos para testar, tá entendendo? Para nossa condição aqui do Ceará. Então, sempre tem que estar refazendo e } \\
\text { trocando estas informações de mercado para que o produto seja bem aplicado no consumidor final, que é o cliente." (E3) } \\
\text { "Nós temos dentro desse programas, às vezes, a gente disponibiliza às vezes até consultoria para a empresa. A gente faz } \\
\text { encontros com representantes da empresa, tentando alinhar os processos, né, pra tentar melhorar essa relação!" (ANT3) }\end{array}$ \\
\hline
\end{tabular}


Quadro 1 - Resultados da Pesquisa (continuação)

\begin{tabular}{|c|c|}
\hline Gestão de risco & $\begin{array}{l}\text { "Não teve nenhuma pressão não. Teve uma oportunidade de negócio que eu visualizei, né? E eu resolvi investir nisso." (E1) } \\
\text { "Assim, de externa não! Não uma ISO [ou seja, uma certificação comumente relacionada ao meio ambiente em termos da } \\
\text { ISO 14001], temos não! A gente tem a certificação do grupo Enel! A gente é fornecedor do grupo Enel de serviços, que a } \\
\text { gente mantem isso atualizado, porque é um grande grupo, é bem exigente, então essa certificação que faz é até a BVQI } \\
\text { [responsável pela certificação ISO], tá entendendo? Mas outra, não tem não." (E3) } \\
\text { "Com certeza! Inclusive para fazer o financiamento com o banco como fornecedor. O fornecedor ele tem que ter as placas } \\
\text { dentro das formações que a própria legislação exige né? O banco, enquanto a isso, ele é muito conservador. Tem que } \\
\text { está tudo regulado." (ANT1) } \\
\text { "Sim! Nós fizemos... lógico, a gente trabalhou as exigências legais, que é no processo licitatório. Você não pode estar } \\
\text { inventando, porque isso pode ser entendido como uma reserva de mercado." (ANT3) }\end{array}$ \\
\hline Pró-atividade & $\begin{array}{l}\text { "Então, na realidade eu não vou nem dizer que os gestores promovem, mas que toda reunião é tocado no assunto da } \\
\text { sustentabilidade. Até porque isso é um dos argumentos de venda, né? [...]. A gente sempre está falando e destacando a } \\
\text { questão da sustentabilidade para que a gente possa estar sempre mostrando para as pessoas a importância de dizer isso } \\
\text { para os clientes, enfim, para que eles possam estar adquirindo o sistema." (E1) } \\
\text { "Nós temos reuniões semanais e sempre estão nas pautas esta questão de sustentabilidade." (E2) } \\
\text { "A gente promove reuniões para discutir sobre os, como é que eu posso te dizer? Sobre os indicadores da empresa! Tá } \\
\text { entendendo? Mas que está relacionado à sustentabilidade, mas não tem essa agenda da sustentabilidade. Tem agenda } \\
\text { estratégica da empresa." (E3) } \\
\text { "Sobre especificamente este assunto [sustentabilidade], não. Este é um assunto que volta e meia, ou uma hora e outra ele } \\
\text { vem à tona. Mas não existe um dia específico não." (C3) }\end{array}$ \\
\hline
\end{tabular}

\subsubsection{Orientação}

O debate sobre orientação está interligado ao interesse da alta gestão de implantar a sustentabilidade em toda a cadeia de suprimentos (CS). A adoção de uma visão estratégica e aplicação de uma gestão sustentável são de grande importância às empresas do setor de energia, pois a preservação do meio ambiente significa garantir a sustentabilidade do negócio, uma vez que suas operações dependem de recursos naturais e impactam o meio ambiente. Como apresentado no Quadro 1, as empresas entendem haver uma estratégia de sustentabilidade, o que pode ser observado nas falas de E1 e E2. Ao serem indagadas acerca da existência de sustentabilidade no uso de placas solares, as empresas responderam convictamente que sim, pois, a partir do momento que alguém produzia sua própria energia, impedia que uma termoelétrica fosse ativada. Neste contexto, E2 ratifica esta ideia por sua atuação na produção de energia renovável. Vale salientar ainda que todas as empresas afirmaram não ter havido influências em suas tomadas de decisões para a sustentabilidade, o que se alinha com a visão de market-driver de Silva et al. (2020).

No que se refere à interação com os clientes, E3 destaca certo nível de orientação para sustentabilidade. Seguindo o respondente:

"A gente sempre passa para o cliente, numa conjuntura comercial, os benefícios que ele vai ter. É o que a gente sempre fala: a energia solar na questão social, econômica e ambiental [...]. A questão ambiental, não se discute. E na questão social, ela é muito boa porque ela gera muito emprego [...]. E na questão econômica, ela está voando. Então, ela está bem atrelada aos três pilares da sustentabilidade [...]. Então, a gente sempre tenta passar isso para o cliente, a compensação ambiental [...] para o cliente entender que não é só uma questão de retorno de investimento."

Das três empresas entrevistadas, percebe-se que apenas a E1 demonstra pouca preocupação com o TBL, focando a estratégia no sentido apenas econômico, relacionando apenas à busca por clientes. No que diz respeito aos clientes, C1 respondeu que já no ato da venda trabalha a sustentabilidade e que os vendedores já são orientados nesse sentido. Já em relação à sua própria orientação para sustentabilidade, respondeu da seguinte forma:

"Sim claro! Totalmente. O fato da gente não estar mais consumindo tanto a energia da própria Enel tá sendo uma geradora também, então a gente ajuda a sociedade também para conseguir incentivo de que a gente além de não consumir e não sugar tanta energia a gente também está gerando, então a gente está matando todo mundo com luz, né?" 
Os demais clientes estudados não demonstram prezar pela sustentabilidade como parte de sua estratégia, que busca apenas vender, para o comércio não ser obrigado a fechar suas portas. Quanto à importância das placas solares, o mesmo respondeu: "Tem. Tem sim, que é para diminuir os custos e a gente ficar no mercado". No que diz respeito aos clientes, as respostas são muito diversas a depender do ramo em que se insere a empresa e do nível de instrução dos sócios. C1 e C3 demonstraram aprofundamento e interesse no assunto, enquanto C2 pensou apenas nos aspectos econômicos da utilização de energia solar. Aproximando os lados da díade, percebe-se que há entendimento sobre sustentabilidade, mas que a ideia de pertencimento à cadeia de suprimento não se mostra tão claramente. Ou seja, esta visão demonstra ser necessário reforçar a orientação no intuito de fortalecer as ações na região.

Vale salientar que, ainda falando sobre orientação, existe certo envolvimento de atores não tradicionais. Por exemplo, como indicado no Quadro 1, ANT2 está envolvido com a temática e buscando ampliar suas relações com outros atores da cadeia. Também dando especial importância ao tema, ANT3 afirmou que há uma política da empresa de realmente trabalhar com a sustentabilidade, por decisão da direção. Quanto ao relacionamento com os fornecedores, ANT1 afirmou não ter relação com os fornecedores por não ser primordial, não havendo, portanto, relação contratual, mas apenas de parceria, além de afirmar que o cliente com interesse de adquirir placas tem total liberdade na escolha do fornecedor. O mesmo se observa para os demais atores não tradicionais, nos quais demonstra, nesta visão, a necessidade de maior envolvimento de diversas partes da cadeia em busca da sustentabilidade. A esta ideia de adicionar outros atores, Pagell e Wu (2009) denominam reconceituar a cadeia. Dessa forma, tal fato se mostra como um movimento de envolvidos com ações de sustentabilidade.

\subsubsection{Continuidade}

A continuidade está ligada à estabilidade das relações, inclusive seleção de parceiros (Rashidi et al., 2020). De forma geral, esta dimensão apresentou problemas de adequação ao contexto pesquisado, o que tem relação com o pouco reconhecimento dos atores de fazerem parte da CS antes apresentada. Para todas as díades, houve dificuldade de compreensão dos temas e pouca informação, mas apesar disso, ficou claro que os relacionamentos se fazem principalmente por meio de "preço e qualidade; e preço, qualidade e prazo de entrega!" (E2). Tal visão contradiz o entendimento de sustentabilidade antes apresentado, o que sugere que a orientação ainda se limita às ações internas. Já sobre o perfil dos fornecedores, respondeu que conhecem os fornecedores superficialmente, mas que nesse ramo, por ser de energia solar, as empresas trabalham com sustentabilidade. Quanto ao relacionamento com os fornecedores e membros da cadeia de suprimento, os respondentes informaram ser meramente comercial, citando para isso critérios de qualidade do produto, prazo e comunicação.

Existe pouca busca por informação de fornecedores, novamente havendo foco no comercial (ver Quadro 1). Demonstra-se, assim, que a relação das empresas focais com os fornecedores demonstra-se impessoal, baseada em um critério meramente econômico, enquanto com os clientes, trata-se de questão técnica, relativo à manutenção e orientações de utilização. Esta análise ratifica a discussão apresentada anteriormente de que a orientação é parte essencial e necessária, mas que tem havido falhas no processo de alinhamento estratégico demonstrado na relação com os clientes, e na qualidade do produto e do serviço, que é justamente o critério adotado para que o relacionamento perdure. Já quanto aos fornecedores, cujas empresas mostram-se satisfeitas com os serviços, também ligando esta relação à qualidade, tem-se, por exemplo, a E3 que não se preocupa com a relação interpessoal com o fornecedor, exemplificando, portanto, pouca interação entre os atores da cadeia.

Mencionando o que diz respeito aos clientes, a percepção sobre relação com fornecedores é um pouco diferente, o que leva a uma maior consideração de aspectos pessoais como a confiança. Por exemplo, C2 informou que a seleção da empresa de placas solares deu-se a partir de seu contador e do Banco do Nordeste, um ator não tradicional à CS. Já C3 informou que a seleção da empresa deu-se por indicação, seguida de ajustamento de valores e financiamento. Informou, ainda, que na escolha de fornecedores não se atem ao fator da sustentabilidade. Por fim, ressaltou que possui um bom relacionamento com os fornecedores, destacando que é resultado, principalmente, da manutenção entre eles. Observa-se que, em relação aos clientes, apenas C1 demonstra-se interessada na relação dos fornecedores com a sustentabilidade. Os demais entrevistados estão desinteressados no assunto, assumindo um posicionamento meramente econômico na escolha dos fornecedores. Destaca-se que o relacionamento entre fornecedores e clientes limita-se ao âmbito da manutenção do equipamento. Dessa forma, compreende-se que é necessário incentivar maior interação entre os atores, o que inclui os não tradicionais.

\subsubsection{Colaboração}

A colaboração na cadeia de energia solar foca o compartilhamento de informações entre os atores da cadeia de suprimento. Neste sentido, E2, E3, C1 e C3 entendem haver tal compartilhamento, o que está relacionado à manutenção dos equipamentos e a um processo de pós-venda próximo (ver Quadro 1). Reconhece-se que a troca de informações e tecnologias é uma solução positiva para todos os envolvidos e, apesar deste entendimento, E1 e C2 não conseguiram identificar tal perspectiva, o que demonstra alinhamento efetivo apenas na díade E3-C3. 
Vale salientar que as informações compartilhadas não se relacionam à sustentabilidade, limitando-se às questões de funcionamento, meramente técnicas e atinentes a qualquer relação de consumo. Tal visão indica que apesar de haver orientação com visão estratégica, isso não se torna efetivo num contexto de colaboração.

Percebe-se com esta perspectiva, que de forma similar à continuidade, haverá limitações para a cadeia de suprimentos (CS) em estudo, o que pode receber maior atenção pelos membros locais. Neste sentido, acerca do compartilhamento de informações, ANT1 respondeu que repassa informações acerca da aquisição $\square$ mas apenas ao que lhe diz respeito como instituição -, como acesso ao crédito e garantia, aspectos também ressaltados por ANT3 (ver Quadro 1) e afirmados por ANT2 - que respondeu sucintamente não compartilhar informações com os fornecedores de placas. Desse modo, para este setor, no contexto analisado, entende-se que a colaboração não se apresenta como um elemento essencial aplicado para a introdução da Sustentabilidade em Cadeia de Suprimento. Pois, uma vez que a orientação não possui alinhamento entre os diferentes lados das díades, tem-se que a colaboração poderia ser um aspecto a ser melhor explorado, tendo em vista que o compartilhamento beneficia de pronto a todos, que colaboram para o aperfeiçoamento do produto em questão.

\subsubsection{Gestão de Risco}

A gestão de risco para SCS tem relação ao monitoramento, criação de normas e grupos de pressão. Identificouse neste elemento que há forte tendência ao uso de certificações para lidar com potenciais riscos na gestão para sustentabilidade. Por exemplo, verificou-se que as empresas entrevistadas buscam fornecedores com certificação, sendo algumas delas também possuidoras de certificações (ver Quadro 1). Na análise das respostas, é possível perceber que todas as empresas preocupam-se com a qualidade dos fornecedores, buscando, em unanimidade, fornecedores que tenham as certificações. Porém, a exigência própria de certificação é tratada com menos importância.

Quanto ao relacionamento com os clientes, demonstra-se que o mesmo se dá em relação à manutenção em todos os casos, não fugindo ao lógico, já que se trata de um processo técnico de geração de energia, sendo natural o surgimento de dúvidas em longo prazo por parte dos clientes; porém, também não se demonstra que esse relacionamento seja ligado a nenhum outro ponto a não ser o técnico. Dessa forma, em paralelo, pressões são pouco observadas como indicado por E1 (Quadro 1).

No que tange aos clientes, $\mathrm{C} 1$ informou que a fornecedora de placas, por ser geradora de energia, tem certificação própria verificada. Já C2 e C3 afirmaram não verificar tal aspecto como forma de gestão de risco. Dessa forma, e ainda sobre o assunto, identificou-se que os atores não tradicionais possuem uma visão de cuidado em termos de riscos relacionados ao setor, como no exemplo que ANT3 indica:

"Sim, nós temos várias aqui. Nós temos toda uma política de sustentabilidade. Temos uma política de compras sustentáveis [...]. Uma política de coleta seletiva, gestão de resíduos sólidos. Procuramos trabalhar mobilidade urbana das pessoas que trabalham aqui. Então existe um... várias ações que a gente desenvolve aqui dentro do programa de sustentabilidade!"

Com esta perspectiva, percebe-se que há preocupação no setor com monitoramento e normas para sustentabilidade, o que representa gestão de risco para SCS.

\subsubsection{Pró-atividade}

A categoria pró-atividade está relacionada à aprendizagem, gestão de stakeholders, inovação e avaliação do ciclo de vida. Assim como a gestão de risco, há uma visão de processos para SCS. Esta categoria é pouco observada nas três tríades e nos atores não tradicionais pesquisados, pois normalmente as respostas tendem a discutir a orientação para SCS em si. Em outras palavras, foi identificado, nesta pesquisa, que pró-atividade na verdade deveria estar relacionada ao debate de orientação. Também foi possível observar na pesquisa que a pauta sustentabilidade existe (ver Quadro 1), no entanto com uma tendência voltada ao desempenho econômico, principalmente pelo estímulo à economia de energia. Sobre isso, por exemplo, E3 afirma perceber mudanças nos aspectos econômico, social e ambiental, principalmente no sentido de gerar empregos e diminuir a poluição, fato que novamente leva ao entendimento de que a pró-atividade se alinha à visão de orientação e valor entre ao mercado.

Quanto aos clientes, C1 afirmou que a pauta de sustentabilidade sempre é colocada em pauta nas reuniões. De forma contrária, C2 e C3 não identificam elementos de aprendizagem ou gestão de stakeholders. Assim, demonstrouse, com esta análise, que as empresas reconhecem os efeitos positivos que causam na sociedade, nos aspectos econômico, social e ambiental, aliando este resultado à natureza do empreendimento, associando a energia limpa com a sustentabilidade. Acerca dos debates sobre a sustentabilidade, observou-se que E1 utiliza-se deste termo para captação de clientes, como objeto de convencimento, ligando intensamente seu interesse no assunto ao aspecto econômico. As demais entrevistas colocam o tema em pauta, mas não indicando que seja o tema principal, apenas 
um assessório que merece destaque também pela natureza do negócio. Com esta visão, entende-se que ações estratégicas precisam apresentar melhor contribuição para a efetiva introdução de SCS.

\section{DISCUSSÃO}

Na busca por entender a Sustentabilidade na Cadeia de Suprimentos (SCS) no contexto de energia solar, esta pesquisa focou na identificação de quais são os elementos introduzidos em relação à sustentabilidade. Por meio da aplicação e análise crítica do modelo de Beske e Seuring (2014), entende-se haver certos elementos de sustentabilidade que não são aplicados ao contexto de pesquisa. No entanto, foi possível observar que as ações atualmente existentes e as adequações para implantação de energias renováveis já estimulam a SCS (cf. Silva e Figueiredo, 2020), que não se limita àquelas categorias estudadas. Com isso, duas contribuições foram identificadas com esta pesquisa: (1) a identificação de elementos específicos ao setor de energia solar, algo pouco explorado na literatura; e (2) uma análise crítica do modelo, o qual pode ter claras adaptações.

Toma-se como contribuição o foco nas características de energia solar, sendo necessário entender que SCS tornase possível apenas quando aspectos locais são considerados (Fritz e Silva, 2018), fato que foi percebido na pesquisa. $\mathrm{Na}$ primeira contribuição, como o Ceará é o estado com mais incidência de luz e, portanto, possui grandes investimentos para introduzir energia solar, entende-se que a busca por SCS pode partir da implantação de placas solares. Os resultados mostram que a orientação para sustentabilidade é algo essencial neste sentido, o que precisa ser observado e praticado por outros setores para fortalecer a SCS (Ponte e Viana, 2020). Ainda assim, no entanto, tem-se uma ênfase maior em aspectos comerciais, o que afeta a contribuição do setor para SCS. Desse modo, podem ser implementadas estratégias focadas no produto sustentável (Harms et al., 2013; Seuring e Müller, 2008), algo que precisa de maior ênfase no setor e na literatura sobre o tema. Tal fato se alinha ainda ao que foi debatido por Pagell e Wu (2009) no que se refere à implantação de novos modelos de negócios e comportamento pró-sustentabilidade.

A segunda contribuição se refere a uma análise crítica do modelo selecionado para identificar sua aplicabilidade para o contexto de pesquisa. De forma geral foram identificados alguns pontos que merecem destaque. No âmbito da orientação para SCS, de forma similar à Silva et al. (2020) e Vasconcelos et al. (2021), foi identificado que tal dimensão é central para o entendimento da sustentabilidade. Em relação à continuidade, apesar da existência de reconceituação da CS (Pagell e Wu, 2009), identificaram-se problemas na cadeia de energia solar, uma vez que os atores investigados não se sentem parte de uma cadeia de suprimento. Entende-se, portanto, que apesar de atuantes, os atores não tradicionais pouco suportam, neste contexto, a introdução efetiva de SCS. Deve-se considerar ainda para essas categorias que há pouca ênfase na visão social (Bubicz et al., 2019), o que sugere a necessidade de maior interação entre todos os membros da cadeia de suprimento.

No que se refere à colaboração, diferente do que foi identificado por Alves et al. (2018) e Azevedo et al. (2018), tal aspecto foi superficialmente abordado, o que se resume à troca de informações comerciais sem ênfase em sustentabilidade. Adicionalmente, de forma diferente às pesquisas que utilizam o modelo, foi identificada certa ênfase à gestão de risco, o que pode estar ligado aos investimentos requeridos no setor, mas que também se refere à busca por justiça social e ambiental como identificado na pesquisa. Por fim, com foco na categoria pró-atividade, assim como Silva et al. (2020) e Vasconcelos et al. (2021), identificou-se que está categoria não se alinha ao contexto de pesquisa, o que sugere que pró-atividade deve ser um aspecto relacionado à orientação em si. Dessa forma, entende-se que o modelo precisa de claras adaptações para sua aplicação em diversos contextos. De modo geral, mostra-se evidenciado que a sustentabilidade no setor de energia solar ainda está em desenvolvimento no Brasil, com um relacionamento fraco entre os membros da CS, principalmente com atores não tradicionais, que possuem interesses diferenciados, que fogem ao âmbito empresarial.

\section{CONSIDERAÇÕES FINAIS}

A presente pesquisa atendeu ao seu objetivo ao identificar como os elementos de Sustentabilidade na Cadeia de Suprimentos (SCS) vêm sendo introduzido no setor de energia solar, a partir do modelo proposto por Beske e Seuring (2014). Verificou-se com a pesquisa que existem elementos que não se aplicam em sua plenitude, por exemplo, continuidade e pró-atividade, indicando a necessidade de se repensar o modelo. Tal aspecto fica claro em relação às categorias analisadas (orientação, continuidade, colaboração, gestão de risco e pró-atividade) que são de singular importância para o estudo da sustentabilidade na cadeia de suprimento, mas não foram identificadas em sua completude. No caso da colaboração, por exemplo, apesar de não terem sido verificadas ações entre os respondentes, esta surge como essencial para SCS. Dessa forma, tal aspecto sugere que evidencias empíricas são fundamentais para a construção de teoria neste tema.

Observou-se que no setor de energia solar o termo "sustentabilidade" tem real relevância para os atores da cadeia de suprimento. Esta importância se deve ao fato da natureza do próprio negócio, que se baseia na produção de energia a partir de um produto renovável. Por definição, a produção de energia solar já se compatibiliza com o termo $\square$ sustentabilidade $\square$, principalmente com relação ao âmbito ambiental. As empresas focais, em sua maioria, 
demonstraram compreender o significado de sustentabilidade, inclusive em seu termo mais correto, que abrange as três dimensões (econômica, social e ambiental).

Apesar disso, os atores estudados em sua maioria não se sentem parte de uma cadeia de suprimento. Suas relações se pautam em confiança e, acima de tudo, observância de todos os envolvidos quanto às obrigações sustentáveis, que envolvem viabilidade econômica, proteção ambiental e melhores condições de trabalho. No entanto, as empresas não possuem um relacionamento com os fornecedores a ponto de organizarem-se em torno do melhoramento destas questões, ou seja, escolhem seus fornecedores com base em questões econômicas e prosseguem com o contato apenas por questões burocráticas, relativas à manutenção e outras situações de âmbito técnico. A continuidade, por exemplo, apesar de não existir claramente deve ser um aspecto a ser considerado pelos envolvidos na cadeia se suprimento (CS). Com isso, as estratégias das empresas se alinham melhor à perspectiva de orientação por elas apresentada.

Ao longo do estudo percebeu-se que as estratégias não são bem delimitadas e as empresas mostram-se, ainda, desorganizadas em relação à aplicação das técnicas mencionadas no estudo; apesar de, na prática, entenderem a importância da observância da sustentabilidade, ainda que se atenham principalmente às questões econômicas, adaptando-se aos poucos às estratégias de gestão de cadeia de suprimentos. Assim, traz-se com o estudo, então, a contribuição de uma análise empírica e crítica, a qual se chegou à conclusão de que o modelo estudado é utilizado apenas em partes no cotidiano das empresas, sendo sua aplicação integral ainda uma realidade distante na prática de gestão. Dessa forma, tem-se como limitação principal da pesquisa a questão da não transferibilidade dos resultados identificados, o que não invalida o debate teórico realizado. Por fim, novas pesquisas podem ser realizadas para contribuir ou questionar alguns dos resultados desta pesquisa, o que auxilia o avanço da literatura em dois sentidos: (1) repensar modelos para o estudo de SCS e (2) fortalecer o estudo da temática em diversos contextos.

\section{REFERÊNCIAS}

ABDALA, E. C.; BARBIERI, J. C. Determinants of sustainable supply chain: an analysis of mensuration models of pressures and socio-environmental practices. Journal of Operations and Supply Chain Management, [S. I.], v. 7, n. 2, p. 110-123, 2014.

ADESANYA, A., YANG, B.; IQDARA, F. W. B.;YANG, Y. Improving sustainability performance through supplier relationship management in the tobacco industry, Supply Chain Management: An International Journal, [S. I.], v. 25, n. 4, p. 413-426, 2020.

AHI, P.; SEARCY, C. A comparative literature analysis of definitions for green and sustainable supply chain management. Journal of cleaner production, [S. I.], v. 52, p.329-341, 2013.

ALVES, A. P. F.; SCHULTZ, G.; DE BARCELLOS, M. D. Understanding sustainable supply chain coordination: a review of publications in brazilian journals. Revista Ciências Administrativas, [S. I.], v. 24, n. 3, p. 1-17, 2018.

ALVES, A. P. F.; SILVA, M. E.; SANTOS, J. G. Colaboração para a sustentabilidade: práticas de membros de uma cadeia de suprimentos do Rio Grande do Sul. Revista de Gestão Social e Ambiental, [S. I.],v. 12, n. 1, p. 2-20, 2018.

ANSARI, Z. N.; KANT, R. Exploring the framework development status for sustainability in supply chain management: a systematic literature synthesis and future research directions. Business Strategy and the Environment, [S. I.], v. 26, n. 7, p. 873-892, 2017.

AZEVEDO, S. G.; SILVA, M. E.; MATIAS, J. C.; DIAS, G. P. The Influence of collaboration initiatives on the sustainability of the cashew supply chain. Sustainability, [S. I.], v.10, n. 6, p. 1-29, 2018.

BALLOU, R. H.; GILBERT, S. M.; MUKHERJEE, A. New managerial challenges from supply chain opportunities. Industrial marketing management, [S. I.], v. 29, n. 1, p. 7-18, 2000.

BESKE, P. Dynamic capabilities and sustainable supply chain management. International journal of physical distribution \& logistics management. [S. I.], v. 42, n. 4 p. 372-387, 2012.

BESKE, P.; SEURING, S. Putting sustainability into supply chain management. Supply Chain Management: an international journal. [S. I.], v. 19, n. 3, p. 322-331, 2014.

BRITO, R. P.; BERARDI, P. C. Vantagem competitiva na gestão sustentável da cadeia de suprimentos: um metaestudo. RAE-Revista de Administração de Empresas, [S. I.], v. 50, n. 2, p. 155-169, 2010. 
BUBICZ, M. E.; BARBOSA-PÓVOA, A. P. F. D.; CARVALHO, A. Incorporating social aspects in sustainable supply chains: trends and future directions. Journal of Cleaner Production, [S. I.], v. 237, n. 2, p. 117500, 2019.

CAPARELLI, C. E.; BARROS, L. A. B. C.; DIAS, E. A. Sustentabilidade e retorno ao acionista: Um estudo sobre o índice de sustentabilidade empresarial. São Paulo: FEA, 2010.

CARVALHO, A. P. D. Gestão sustentável de cadeias de suprimento: análise da indução e implementação de práticas socioambientais por uma empresa brasileira do setor de cosméticos. 2011.Tese. (Doutorado em Administração de Empresas) - Fundação Getúlio Vargas, São Paulo, 2011.

CRESWELL, J. W. Procedimentos de métodos mistos. Creswell, JW projeto de pesquisa: métodos qualitativo, quantitativo e misto. 2. ed. Porto Alegre: Artmed, 2007.

DENZIN, N. K.; LINCOLN, Y. S. (ed.). Handbook of qualitative research. 2. ed. Califórnia: Sage Publications. 2000.

ELKINGTON, J. (ed.). Cannibals with forks: the triple bottom line of 21st century business Oxford: Capstone. 2002.

FEIL, A. A.; SCHREIBER, D. Sustentabilidade e desenvolvimento sustentável: desvendando as sobreposições e alcances de seus significados. Cadernos EBAPE. BR, [S. I.], v. 15, n. 3, p. 667-681, 2017.

FRITZ, M. M. C.; SILVA, M. E. Exploring supply chain sustainability research in Latin America. International Journal of Physical Distribution \& Logistics Management, [S. I.], v, 48, n. 8, p. 818-841, 2018.

GIL, A. C. Como elaborar projetos de pesquisa. 5. ed. São Paulo: Atlas, 2010.

GODOY, A. S. Estudo de caso qualitativo. In: GODOI, CK. Pesquisa qualitativa em estudos organizacionais. São Paulo: Saraiva, 2006. cap. 4

HARMS, D.; HANSEN, E. G.; SCHALTEGGER, S. Strategies in sustainable supply chain management: an empirical investigation of large German companies, Corporate social responsibility and environmental management, [S. I.], v. 20, n. 4 , p. 205-218, 2013.

JIA, F.; ZULUAGA-CARDONA, L.; BAILEY, A.; RUEDA, X. Sustainable supply chain management in developing countries: an analysis of the literature. Journal of Cleaner Production, [S. I.], v. 189, p. 263-278, 2018.

KETOKIVI, M.; CHOI, T. Renaissance of case research as a scientific method. Journal of Operations Management, [S. I.], v. 32, n. 5, p. 232-240, 2014.

KHALID, R. U.; SEURING, S.; BESKE, P.; LAND, A.; YAWAR, S. A.; WAGNER, R. Putting sustainable supply chain management into base of the pyramid research. Supply Chain Management: An International Journal, [S. I.], v. 20, n. 6, p. 681-696.

LAUREANO, L. A.; AZEVEDO, S. R. Rumo ao capitalismo sustentável. Cadernos de Ideias. Nova Lima: Fundação Dom Cabral, 2012.

LUMMUS, R. R.; VOKURKA, R. J. Defining supply chain management: a historical perspective and practical guidelines. Industrial Management \& Data Systems, [S. I.], v. 99, n. 1, p. 11-17, 1999.

MAGON, R. B.; THOMÉ, A. M. T.; FERRER, A. L. C.; SCAVARDA, L. F. Sustainability and performance in operations management research. Journal of Cleaner Production, v. 190, p. 104-117, 2018.

MARIA, G. P.; CARETA, C. B. Mensuração e divulgação do desempenho sustentável por empresas da cadeia de suprimentos de alimentos e bebidas brasileira. In: SEMINÁRIO EM ADMINISTRAÇÃO, 21., 2018, São Paulo. Anais [...]. São Paulo: FEA, 2018, p. 1-17.

MAYRING, P. Qualitative content analysis. FQS Forum: Qualitative Social Research, [S. I.], v. 1, n. 2, p. 1-10, Jun. 2000. 
Anais [...]. São Paulo: [s. n.], 2017, p. 1-10.

MENTZER, J. T.; DEWITT, W.; KEEBLER, J. S.; MIN, S.; NIX, N. W.; SMITH, C. D.; ZACHARIA, Z. G. Defining supply chain management. Journal of Business Logistics, v. 22, n. 2, p. 1-25, 2001.

MUNCK, L., Dias, B. G.; SOUZA, R. B. de. Sustentabilidade organizacional: uma análise a partir da institucionalização de práticas ecoeficientes. REBRAE, [S. I.], v. 1, n. 3, p. 285-295, 2008.

NEUTZLING, D. M.; SILVA, M. E. A sustentabilidade em cadeias de suprimento a partir da visão de recursos e capacidades. Revista Ciências Administrativas, [S. I.], v. 22, n. 1, 42-71, 2016.

PAGELL, M.; SHEVCHENKO, A. Why research in sustainable supply chain management should have no future. Journal of supply chain management, [S. I.], v. 50, n. 1, p. 44-55, 2014.

PAGELL, M.; WU, Z. Building a more complete theory of sustainable supply chain management using case studies of 10 exemplars. Journal of supply chain management, [S. I.], v. 45, n. 2, p. 37-56, 2009.

PEREIRA, R. D. C. D. F.; BELLINI, C. G. P. A perspectiva da díade em relacionamentos entre empresas e clientes de software. Gestão. Org-Revista Eletrônica de Gestão Organizacional, [S. I.], v. 5, n. 2, p. 94-117, 2010.

PONTE, R. C. D. V.; VIANA, F. L. E. O tripé da estratégia e a sustentabilidade em cadeias de suprimento de alimentos: um estudo na cadeia da cajucultura. 44., 2020, In: Anais[...] 44., EnANPAD, 2020. p.

RASHIDI, K.; NOORIZADEH, A.; KANNAN, D.; CULLINANE, K. Applying the triple bottom line in sustainable supplier selection: a meta-review of the state-of-the-art. Journal of Cleaner Production, [S. I.], p. 122001, 2020.

ROY, V.; SCHOENHERR, T.; CHARAN, P. The thematic landscape of literature in sustainable supply chain management (SSCM): a review of the principal facets in SSCM development. International Journal of Operations \& Production Management. [S. I.], v. 38, n. 4, p. 1091-1124, 2018.

SAMPIERI, R. H.; COLLADO, C. F.; LUCIO, P. B. Metodologia de pesquisa. 3. ed. São Paulo: McGraw-Hill, 2006.

SAUER, P. C.; SEURING, S. Sustainable supply chain management for minerals. Journal of Cleaner Production, [S. I.], v. 151, p. 235-249, 2017.

SCHRETTLE, S.; HINZ, A.; SCHERRER-RATHJE, M.; FRIEDLI, T. Turning sustainability into action: explaining firms' sustainability efforts and their impact on firm performance, International Journal of Production Economics, [S. I.], v. 147, p.73-84, 2014.

SEURING, S. Supply chain management for sustainable products - insights from research applying mixed methodologies. Business and Strategy and the Environment, [S. I.], v. 20, p. 471-484, 2011.

SEURING, S.; MÜLLER, M. From a literature review to a conceptual framework for sustainable supply chain management. Journal of cleaner production, [S. I.], v. 16, n. 15, p. 1699-1710, 2008.

SILVA, M. E.; ALVES, A. P. F.; DIAS, P.; NASCIMENTO, L. F. M. The role of orientation towards sustainability in supply chains: Insights from empirical experiences. Benchmarking: An International Journal, [S. I.],v. 27, n. 4, p. 1-22, 2020.

SILVA, M. E.; FIGUEIREDO, M. D. Practicing sustainability for responsible business in supply chains. Journal of Cleaner Production, [S. I.], v. 251, p. 119621, 2020.

SILVA, M. E.; FRITZ, M. M.; NUNES, B. Scanning insights on sustainability and supply chain management in Brazil. Journal of Operations and Supply Chain Management, [S. I.], v. 10, n. 1, p. 33-54, 2017.

SILVA, M. E.; NASCIMENTO, L. F. M. pensando a intersecção entre sustentabilidade e cadeia de suprimento. Revista Espacios, [S. I.], v. 37, n. 4, p. 42-71, 2016.

STOFFEL, J. A.; COLOGNESE, S. A. O desenvolvimento sustentável sob a ótica da sustentabilidade multidimensional. Revista da FAE, [S. I.], v. 18, n. 2, p. 18-37, 2015. 
VASCONCELOS, D. C.; VIANA, F. L. E.; SOUZA, A. L. Circular economy and sustainability in the fresh fruit supply chain: a study across Brazil and the UK. Latin American Business Review, [S. I.], v. 17, n. 4, p. 1-17, 2021.

YIN, R. K. Estudo de Caso: planejamento e métodos. Bookman, 2015.

\section{Contato:}

Mariana Fernandes Alves

E-mail: marifalves@edu.unifor.br

Minelle Enéas da Silva

E-mail: minele.adm@gmail.com 